\title{
Evaluation of self-reported work ability and usefulness of interventions among sick-listed patients
}

\author{
Charlotte Wåhlin, Kerstin Ekberg, Jan Persson, Lars Bernfort and Birgitta Öberg
}

\section{Linköping University Post Print}

N.B.: When citing this work, cite the original article.

The original publication is available at www.springerlink.com:

Charlotte Wåhlin, Kerstin Ekberg, Jan Persson, Lars Bernfort and Birgitta Öberg, Evaluation of self-reported work ability and usefulness of interventions among sick-listed patients, 2013, Journal of occupational rehabilitation, (23), 1, 32-43.

http://dx.doi.org/10.1007/s10926-012-9376-y

Copyright: Springer Verlag (Germany) http://www.springerlink.com/?MUD=MP

Postprint available at: Linköping University Electronic Press http://urn.kb.se/resolve?urn=urn:nbn:se:liu:diva-76147 


\section{Evaluation of self-reported work ability and usefulness of interventions among sick-listed patients}

Charlotte Wåhlin $^{1}$, Kerstin Ekberg ${ }^{2,3}$, Jan Persson ${ }^{4}$, Lars Bernfort ${ }^{4}$ and Birgitta Öberg ${ }^{1}$

${ }^{1}$ Division of Physiotherapy, ${ }^{2}$ National Centre for Work and Rehabilitation, Department of

Medical and Health Sciences, ${ }^{3}$ Helix Vinn Excellence Centre and ${ }^{4}$ Division of Health Care

Analysis, Department of Medical and Health Sciences, Linköping University, Linköping,

Sweden

Correspondence address: Charlotte Wåhlin, Division of Physiotherapy, Department of Medical and Health Sciences, Linköping University, SE 58183 Linköping, Sweden.

Tel.: +461010328 71. E-mail: charlotte.wahlin@liu.se

Running head: Evaluation of work ability and interventions 


\begin{abstract}
Aim To describe the types of intervention offered, to investigate the relationship between the type of intervention given, patient-reported usefulness of interventions and the effect on selfreported work ability in a cohort of sick-listed patients with musculoskeletal disorders (MSD) or mental disorders (MD).
\end{abstract}

Methods A prospective cohort study was performed including 810 newly sick-listed patients (MSD 62\% and MD 38\%). The baseline questionnaire included sociodemographic characteristics and measures of work ability. The 3-month follow-up questionnaire included measures of work ability, type of intervention received, and judgment of usefulness.

Results Twenty-five percent received medical intervention modalities (MI) only, 45\% received a combination of medical and rehabilitative intervention modalities (CRI) and $31 \%$ received workrelated interventions combined with medical or rehabilitative intervention modalities (WI). Behavioural treatments were more common for patients with MD compared with MSD and exercise therapy were more common for patients with MSD. The most prevalent workplace interventions were adjustment of work tasks or the work environment. Among patients with MD, WI was found to be useful and improved work ability significantly more compared with only MI or CRI. For patients with MSD, no significant differences in improved work ability were found between interventions.

Conclusions Patients with MD who received a combination of work-related and clinical interventions reported best usefulness and best improvement in work ability. There was no difference in improvements in work ability between rehabilitation methods in the MSD group. There seems to be a gap between scientific evidence and praxis behaviour in the rehabilitation process. Unimodal rehabilitation was widely applied in the early rehabilitation process, a multimodal treatment approach was rare and only one-third received work-related interventions. It remains a challenge to understand who needs what type of intervention.

Keywords Musculoskeletal disorders; Mental disorders; Sick leave; Self-reported; Work ability; Usefulness; Interventions, Sweden 


\section{Introduction}

Patients with musculoskeletal disorders (MSD) and mental disorders (MD) often have impaired work ability and reduced functional capacity (1). These conditions account for the majority of sick leave in Sweden (2-4), and in many western countries. The time until return to work after sick leave varies depending on several factors, such as personal health resources, the severity of the health condition, work environment factors, the financial compensation system, as well as receipt of tailored interventions and satisfaction with health care interventions (5-8).

Improvement in work ability and functional capacity is a common goal of rehabilitation (9). Previous research suggests that occupational factors should be addressed early in the rehabilitation process by employers and health care providers in order to tailor interventions according to needs of the patient (10-13). Contacts with health care are often complex with many actors involved $(5,6,11)$, and increased communication between physicians in primary health care and occupational health services is essential $(14,15)$. There is some evidence that collaboration between the sick-listed patient, health care providers and the employer favours the rehabilitation process $(10,16-18)$. Patients consider their contact with the health care provider as an important part of their rehabilitation that affects recovery and return to work (RTW) $(17,19$ 22).

There is increasing interest in learning from patients' experiences of the rehabilitation process in order to improve the quality of health care, rehabilitation services, and interventions aimed at enhancing RTW (20, 22-24). In Sweden, this interest was emphasized when the government introduced reforms in 2008 in the national sickness insurance system (the rehabilitation chain), focusing on early assessments of work ability, right to benefits and the use of evidence-based methods for RTW. The type of health care interventions that are actually offered in clinical practice for sick-listed patients still remains to be studied. Among patients with MSD, health care utilization seems to increase for the following factors: the severity of the health problem, if sick-listed, and a low level of educational $(11,25-27)$. However, studies that include evaluation of patient satisfaction and usefulness of interventions for newly sick-listed patients with MSD or MD have been performed to a limited extent. Dionne et al. [24] found that poor satisfaction with

primary health care may delay RTW for patients with back pain (28). Opinions about satisfaction and reported usefulness were found to be important measures for evaluating a RTW program based on graded activity combined with work-related interventions (7). 
One way to tailor interventions is to determine patients' preferences for interventions, expectations and obstacles to recovery, because preferences influence the outcome of interventions and RTW $(13,18,29,30)$. Mergl et al. (31) found that patients with depression who received the preferred intervention in primary health care (medication or psychotherapy) responded better to the intervention. The patient's motivation may be strengthened by participation in decisions about intervention strategies $(18,30,32)$. Early assessments with structured risk factor screening and specific interview questions that include occupational factors can be helpful for clinicians to classify different types of sick-listed patients with low back pain, as a basis for dialog concerning choice of interventions and for tailoring individualized interventions $(12,13,33)$.

Few studies have addressed patient-reported usefulness of interventions and the effect on work ability among sick-listed patients with MSD or MD. The patients' experience of the rehabilitation process may be useful in order to improve how early interventions should be scheduled to facilitate RTW. Patients' reported usefulness of interventions can help in making a shared decision with rehabilitation providers on the choice of interventions.

More research is needed on methods for selecting interventions in collaboration with the patient that enhance RTW for sick-listed patients. The objective of this study was to describe the types of interventions offered, investigate the relationship between the type of intervention given, patient-reported judgment of the usefulness of different types of interventions, and how self-reported work ability is affected by different interventions in a cohort of sick-listed patients with MSD or MD.

\section{Methods}

This prospective cohort study comprised individuals who sought primary health care or occupational health services for MSD or MD and were sick-listed. A total of 1376 patients were recruited between June 2008 and December 2009; 413 subjects were lost because they did not return the baseline questionnaire. Thus, the final study sample consisted of 963 subjects on sick leave. All subjects were followed up after 3 months by a questionnaire and 810 subjects (84\%) returned the 3-month questionnaire. Sickness certificates were issued from physicians in primary health care (93\%) and from physicians in occupational health services (7\%).

The inclusion criteria were: being on sick leave for MSD or MD, aged 18-65 years and able to speak Swedish. Inclusion was based on an ICD-10 diagnosis on the sickness certificate issued by 
a physician. The ICD-10 diagnoses for MSD were mostly dorsopathies (M50-54), soft tissue disorders (M70-79), other joint disorders (M20-25) and injuries (S00-T98). For MD, the diagnoses included were mostly depression (F32-39), reactions to severe stress and adjustment disorders (F43), other anxiety disorders (F41), and burnout/vital exhaustion (Z73). Exclusion criteria were: sick leave for the same diagnosis in the previous month or sick leave due to a psychiatric diagnosis such as schizophrenia; psychotic disorders; neurological disorders; rheumatic disease; fracture; or pregnancy. Every second week, the research team monitored all patients who became sick-listed at one of 39 primary health care centres in the region and 5 occupational health service centres. Health care professionals at the clinics and the research team were involved in the recruitment of newly sick-listed patients. Recruitment took place mainly by telephone and by scanning the computerized case records of patients who obtained a sick-leave certificate at the health care centres.

All subjects received written and verbal information about the study before consenting to participate. The baseline questionnaire was sent to the patients directly after they were included. The patients were followed up after 3 months using a postal questionnaire. If necessary, they were reminded by telephone a maximum of twice before being classified as non-responders. Ethical approval was granted by the local Ethics Committee (Dnr M78-05).

\section{Self-reported Measures at Baseline}

The baseline questionnaire included sociodemographic variables (age, sex, marital status, educational level, occupation), and work ability. The patient's educational level was categorized into lower education (mandatory school and high school) and higher education (university studies). In Sweden, sickness benefit can be paid at $25 \%, 50 \%, 75 \%$ or $100 \%$, depending on assessment of the degree of work ability. The degree of sick leave was presented as full time or part time $(75 \%, 50 \%$ and $25 \%)$. Profession was coded according to the Swedish standard for occupational classification (Statistics Sweden) with 9 occupational groups categorized into white collar (managers, academics, etc.), pink collar (care, service, salespersons, etc.), and blue collar (industry, etc.). In this study, patients judgment of work ability was measured with the first item "current work ability compared with the lifetime best" in the Work Ability Index (WAI) (34). The score was graded from 0 to 10 , where 0 stands for completely unable to work and 10 stands for work ability at its best. The first item of the WAI has previously been used to assess work ability among sick-listed persons by Ahlstrom et al. (35), who found that the item is a good 
alternative to the WAI. Alavinia et al. (36) have shown that this item has predictive power for future disability.

\section{Self-reported Measures at 3-Month Follow-up}

The 3-month questionnaire focused on which interventions were implemented during the first 3 months on sick leave and included questions on the type of visits with health care providers (primary health care, occupational health service, and private health service), the type of intervention received, and judgment of usefulness of the interventions. Patients judgment of work ability was followed up using the first item in the WAI (34-36). In addition, patients were specifically asked about the effect on work ability due to health care contacts on a 5-point scale with anchor points ranging between "yes, my work ability is much improved" and "no, my work ability has become much worse". The scores were dichotomized into two groups: work ability improved (values 5 and 4) and work ability not improved (value 1-3).In order to not overestimate positive change the alternative "unchanged" (value 3) was categorize to the group "not improved".

Information on medical intervention modalities and rehabilitative intervention modalities (RIMs) was derived through open questions in the questionnaire concerning the type of health care contact and the type of intervention. The patient's judgment of the usefulness of medical intervention modalities and rehabilitative intervention modalities was measured using a 5-point scale with anchor points ranging between "very good usefulness" and "very poor usefulness". A similar evaluation of patients' self-reported satisfaction with health care was used by Lambeek et al. (7) and van Oostrom (18) also using a 5-point scale. In our study, the median value of all specific usefulness ratings of the interventions was used as a measure of overall usefulness.

Reported interventions were categorized in several steps. First, all interventions were listed for each patient. Second, all interventions were categorized into types of interventions. Medical intervention modalities were categorized into three types: medical treatment, medical investigation and other medical treatment. The medical intervention modalities were not considered to be rehabilitative interventions.

The RIMs performed at the clinic were categorized into 6 types: health care advice, behavioural treatment (therapeutic conversation, cognitive therapy, body awareness), exercise therapy/physical activity, manual treatment (manual, acupuncture/transcutaneous electrical nerve 
stimulation), ergonomic/activities of daily living, equipment/orthosis and other). In this study, a multimodal treatment approach was defined as receiving two or more RIMs.

Information on work-related interventions was derived through the following open question: "What interventions/changes have been made at the work place in order to facilitate your RTW?". The patient's description of work-related interventions performed at the workplace was categorized. The work-related interventions were categorized into 6 types: ergonomic, adjustments to work tasks/work environment, change of work tasks/employment, change to working hours, rehabilitation support and other work-related interventions. Classification difficulties concerning all interventions were discussed in the research group until consensus was reached. The occurrence of any of these interventions was coded as WI.

\section{Three Subgroups of Interventions (MI, CRI, WI)}

Each patient's description of interventions was categorized into three groups based on the interventions they received; three types of rehabilitation process were identified. The group referred to as the medical intervention group (MI) in this article received only medical intervention modalities. Those who received a combination of medical intervention modalities and rehabilitative intervention modalities are referred to as the clinical rehabilitation intervention group (CRI). The third group includes those who received work-related interventions in addition to medical intervention modalities or RIMs and are referred to as the work-related intervention group (WI). In this study, the results are presented separately for the MSD and MD diagnostic groups. Hence, the three intervention subgroups clearly differ with regard to which interventions they were offered.

\section{Statistical Methods}

All statistical data were analysed using the Statistical Package for the Social Sciences (SPSS) program (version 18.0). A descriptive analysis for the total population and subgroups was carried out using proportions, means and standard deviations for the variables assessed. The analyses were performed in two diagnostic groups (MSD and MD) separately and in the three intervention types (MI, CRI, WI). Group comparisons were made using the independent sample $t$ test, Pearson's $\chi^{2}$ test and ANOVA with the Bonferroni post hoc test for all pair-wise comparisons. ANCOVA with age and sex as covariates was used in analyses comparing the three intervention types. For all group comparisons, the level of significance was set at $p<0.05$ (two-sided) and 95\% confidence intervals were used when appropriate. 


\section{Results}

Of the 1376 invited participants, 963 patients returned the baseline questionnaire. The 413 non-responders were significantly younger (42.2 years, SD 10.93) than the responders (46.0 years, SD 11.06) $(p<0.001)$, and included more men $(p=0.02)$. The groups did not differ regarding the distribution of a diagnosis of MD and MSD $(p=0.08)$. Eight hundred and ten patients returned the 3-month follow-up questionnaire. The 153 non-responders of the baseline cohort were significantly younger when comparing age distribution $(p=0.04)$, although no differences were found in distributions of $\operatorname{sex}(p=0.24)$ and diagnosis $(p=0.8)$.

The 3-month follow-up cohort comprised 810 patients (583 women and 227 men). The mean age was 46.3 years (SD 10.94 years). MSD was the most common diagnosis (499 patients, 62\%). The MSD group was significantly older $(p<0.001)$, included more men $(p<0.001)$, and had a lower educational level $(p<0.001)$ compared with patients with MD (Table 1). White collar professions were more common in the MD group (44\%) than in the MSD group (18\%), and blue collar professions were less common in the MD group (14\%) than in the MSD group (40\%) $(p<0.001)$. Among blue collar professions, the most common occupations were cleaners, construction workers, machine operators, professional drivers, and shop assistants. In the MSD group, $74 \%$ received full-time sickness benefit and in the MD group, $63 \%$ received full-time sickness benefit $(p<0.05)$.

All patients had at least one consultation with a physician in primary health care $(93 \%)$ or in occupational health services $(7 \%)$ for initial assessment of the medical condition and the issuance of sickness certification. The majority of the population was on full-time sick leave $(64 \%)$ and $36 \%$ on half-time sick leave. The analysis showed that $24 \%(n=193)$ were in the MI category; $45 \%(n=368)$ were in the CRI category, and $31 \%(n=249)$ were in the WI category (Table 2). Patients with MD were significantly more prevalent in the group who received WI compared with the two other intervention types $(p<0.001)$.

\section{Comparison of Intervention Groups (MI, CRI and WI) Within MSD and MD}

For MD patients, those who received WI were significantly younger compared with those who received MI: mean age for MI, 47 years (SD 11.7 years ); for CRI, 44 years (SD 11.1 years); for WI, 42 years (SD 9.9 years) $(p<0.05)$. Those who received WI also had more education in comparison with the two other intervention types: MI, 30\% with higher education; CRI, 30\%; WI, 55\% ( $p<0.000)$. White collar professions were more common among those who received WI 
(60\%) in comparison with those who received CRI $(36 \%)$ or MI $(24 \%)(p<0.001)$. There was no gender difference between the intervention types among patients with MD, and the degree of sick leave did not differ at baseline.

For MSD patients, those who received WI, were significantly younger compared with those who received MI: mean age for MI, 50 years (SD 10.5 years); mean age for CRI, 48 years (SD 11 years); mean age for WI, 46 years (SD 10.3 years) $(p<0.05)$. Those who received WI were also more educated in comparison with those who received CRI: MI, $17 \%$ with higher education; CRI, 15\%; WI, 27\% ( $p<0.05)$. There was no gender difference between the intervention types among MSD patients. Part-time sick leave was more prevalent among those who received WI (MI, 21\%; CRI, 24\%; WI, 37\%; $p<0.01)$.

Table 2 presents the distribution of interventions, patients' judgment of specific usefulness of medical intervention modalities and RIMs and the frequency of work-related interventions in the diagnostic groups. For patients with MD, medical treatment was more common compared with those with MSD $(p<0.05)$. For patients with MD, medical treatment and behavioural treatment were the most commonly received clinical interventions. For patients with MSD, medical treatment and exercise therapy/physical activity were the most common treatment approaches. Patients with MD reported medical treatment $(p<0.001)$ and medical investigations $(p<0.05)$ as significantly more useful compared with patients with MSD.

Among the 6 types of RIMs, behavioural treatments were more common for patients with MD $(65 \%)$ compared with those with MSD $(10 \%)(p<0.001)$. Significantly more patients with MSD received exercise therapy/physical activities $(p<0.001)$ and manual treatment $(p<0.001)$. Health care advice was reported as significantly more useful by patients with $\operatorname{MD}(p<0.05)$; there was no difference between the diagnostic groups in judgment of usefulness of all other RIMs. The most common work-related intervention for both diagnostic groups was adjustment of work tasks/work environment (42-43\%). Significantly more patients with MD received rehabilitation support (31\%) compared with patients with MSD (18\%) $(p<0.05)$.

\section{Combination of RIMs}

Among the total population, $72 \%(n=581)$ received RIMs (data not shown). Patients with MD received significantly more RIMs compared with patients with MSD (77\% versus $68 \%, p<0.01)$. The frequency of receiving one, two, three or more RIMs was analysed for those patients who received RIMs (Fig. 1). About half of the patients in both diagnostic groups received unimodal 
treatment (one type of RIM, MSD 48\% and MD 53\%). Thirty-six percent of the total study population received a combination of two or more RIMs. Significantly more patients with MSD received 3 or more RIMs compared with patients with MD $(p<0.05)$. Significantly more patients with MD reported better effect of health care contacts on work ability with one or two RIMs compared with patients with MSD (one RIM, $p<0.05$; two RIMs, $p<0.05$ ). No significant difference was found for three or more RIMs between the diagnostic groups $(p=0.06)$ (data not shown).

\section{Patient-reported Usefulness of Types of Interventions}

Among patients with MD, WI was reported as more useful compared with the two other intervention types (WI versus MI, $p<0.001$ and WI versus CRI, $p<0.01$ ) (Table 3). Significantly more patients with MD who received WI reported better effect of health care contacts on work ability compared with the other two intervention groups $(p<0.001)$. For patients who had MSD, there was a significant difference between the intervention types concerning judgment of overall usefulness; WI was reported to be more useful compared with MI $(p<0.05)$, but no difference was found concerning the reported effect of health care contacts on work ability.

For patients with MD, self-reported work ability at baseline was significantly better in the MI group compared with the other two intervention types (MI versus CRI, $p<0.05$ and MI versus WI, $p<0.01$ ) (Table 3). Self-reported work ability at 3 months follow-up was significantly lower for CRI compared with the other two intervention types ( $p<0.001$ and $p<0.05$ ). The MD group improved their work ability most if they received WI $(p<0.05)$. No significant difference in work ability at baseline was found for patients with MSD, and self-reported work ability at the 3month follow-up was significantly worse for patients who received CRI compared with those who received WI $(p<0.001)$.

\section{Patient-reported Usefulness Between Diagnostic Groups}

For patients with MD receiving WI, the overall judgment of usefulness of interventions was significantly better (4.1) compared with patients with MSD receiving the same type of interventions (4.1 versus 3.5) $(p<0.001)$. Patients with MD also reported significantly better usefulness of CRI compared with patients with MSD (3.8 versus 3.2) $(p<0.001)$. The change in work ability was significantly better for patients with MD who received WI (3.2) compared with patients with MSD (2.2) $(p<0.001)$. Significantly more patients with MD (68\%) reported that 
their intervention and contact with health care improved their work ability compared with patients with MSD (51\%) $(p<0.001)$.

\section{Discussion}

In this cohort study of newly sick-listed patients with MSD or MD, the analyses focused on patient judgment of usefulness of early interventions in the rehabilitation process. The main findings were that patients with MD who received a combination of work-related interventions and medical or clinical rehabilitation interventions reported best usefulness of interventions and best effect of health care contacts on work ability. Patients with MSD who belonged to the workrelated intervention group reported significantly higher usefulness compared with those belonging to the medical intervention group.

Patients with MD were more satisfied with early interventions and they improved their reported work ability compared with patients with MSD, which may reflect that the expectations of interventions were met to a higher degree for patients with MD. Previous studies have shown that patients' treatment satisfaction may be related to expectations and preferences for treatment, adherence to treatment and treatment success $(24,31,37,38)$. For example, Wickizer et al. (38) found that, among injured employees, those who reported less satisfaction with treatment were more likely to receive compensation for inability to work.

\section{Work-related Interventions}

As patients with MD were more often on part-time sick leave, work-related interventions might be given at an earlier stage than for patients with MSD. More patients with MD were also given WI compared with patients with MSD. As suggested by Sieurin et al. (39), work-related interventions provide opportunities for employees with lower work ability to stay in work. Van Oostrom et al. (18) found that reported usefulness of participatory work intervention was high among sick-listed employees with distress. In their study, the employer together with the employee found solutions for identified obstacles related to mental workload, stress, and communication. In a review by Michie et al. (40) it was concluded that several of the workrelated variables associated with high levels of psychological ill health have potential to change with appropriate work-related interventions. Furthermore, a recent study by Hultin et al. (41) showed that stress at work or problems in workplace relationships can reduce work ability and be a trigger for sick leave. This cause of sick leave may be improved if work-related interventions are addressed to the problems causing the sick-leave spell. We also found that rehabilitation 
support from the workplace, including support from the employer, workmates and other stakeholders, which is found to be important in the process of returning to work $(20,21)$, was given to a higher degree for patients with MD compared with patients with MSD.

The rehabilitation process has to be understood in each national context and considering the different systems, including personal, workplace, health care and insurance systems (42). In Sweden, work-related interventions are initiated by the employer because they are responsible for providing workplace rehabilitation and making adjustments to the work environment according to the Work Environment Act. Interventions at the workplace are mainly delivered by occupational health services if their company has signed up for this service and is sought by the employer. However, an economic incentive for employers to take greater responsibility for vocational rehabilitation is lacking and relatively few patients in the present study described work-related interventions in which the health care professionals were involved at the workplace. Access to vocational rehabilitation and work interventions seems to be scarce in Sweden $(5,43)$

The importance of providing work-related interventions and adaptation of work for sick-listed patients with $\operatorname{MD}(18,21,44)$ and for patients with $\operatorname{MSD}(9,10,23,45,46)$ is underscored by previous research. It is suggested that employers should have an active role in adapting the workplace for sick-listed patients in order to enhance possibilities for sustainable RTW, but this is not implemented for most patients according to our study. As previously reported by Wåhlin et al. (47), among 699 sick-listed patients with employment, a combination of clinical and workrelated interventions increased the possibility of RTW for patients with MD at 3-month followup. For patients with MSD, better health, better work ability and positive expectations of RTW were associated with RTW. In total, three-quarters of the study population returned to work within 3 months.

From a patient perspective, it appears that support and adjustment at the workplace is a facilitating prerequisite for RTW (19-21), and specific goals for each patient can benefit the RTW process $(18,30,32)$. We found that adjustments to work tasks or the work environment were the most prevalent interventions at the workplace for both diagnostic groups. This is in accordance with de Rijk et al. (23) who found that work modifications were commonly given to sick-listed patients with MSD and MD, and with van Oostrom et al. (18) who found that work design and organization were frequently used for distressed employees. However, there are several obstacles when implementing interventions at the workplace. A study by Coole et al. (48) showed that several patients with back pain found that they had to rely on their own ability to 
make adjustments at work because their employers' knowledge was lacking and access to occupational health services seemed to be poor. The reasons why patients with MSD in our study did not perceive the same usefulness of WI as patients with MD might be a reflection of a more severe health condition, improvement in work ability was lower and they had more physically demanding work conditions. Furthermore, work modifications that require more preparation and have a larger impact seem to be applied more often later in the RTW process (23).

\section{Medical and Clinical Rehabilitative Interventions}

When analysing the specific judgment of usefulness of each intervention, we found that patients with MD reported significantly better usefulness of medical treatment compared with patients with MSD. Only a minority of depressed patients seeking primary health care prefer medication; most prefer individual counselling $(29,49)$. Receiving psychosocial care is associated with higher satisfaction with mental health care for patients with anxiety disorder, whereas age, gender, illness burden and receipt of pharmacotherapy were not (24). The most common intervention for patients with MD was behavioural treatment (therapeutic conversation, cognitive therapy, body awareness) and the judgment of usefulness was high. Less than $10 \%$ of patients with MD received an active physical approach, a remarkably low prevalence given that physical exercise is known to improve patients' health (50) and is recommended in Swedish national guidelines for care of depression (51).

Significantly more patients with MSD received a physically active approach with exercise therapy/physical activity and judgment of usefulness was rated positively. A clinically oriented study by George et al. (37) indicated that satisfaction with treatment was associated with lower pain and disability for patients with back pain. Specific behavioural treatment for patients with MSD (10\%) seems to be underutilized in practice settings. Judgment of usefulness was high among those patients with MSD who received behavioural treatment. The effect of a cognitive treatment approach for patients with persistent MSD has been emphasized in previous research $(30,46,52)$. Tailored behavioural treatment and exercise-based physical therapy can be effective for treating persistent musculoskeletal pain (30).

Manual treatment was given to one-third of patients with MSD and the judgment of usefulness was high. Manual treatment is widely accepted as a treatment strategy for patients with back pain in clinical praxis and is recommended in clinical guidelines in most western countries (53) although there is not enough evidence to recommend one form of manual therapy over another. Evidence supporting manual treatment/spinal manipulation as a single treatment strategy for 
RTW is scarce (54). It is suggested that manual treatment should be combined with exercisebased treatment and a cognitive treatment approach. Less than $10 \%$ of patients with MSD were given ergonomic advice/orthosis provided by health care professionals at the clinic, and just a handful of patients were given ergonomic intervention by health care professionals at the workplace. Considering the effect that ergonomic interventions may have on RTW and functional status $(10,46)$ and the reported usefulness found in our study, it was used sparingly in the early rehabilitation process.

Using a combination of clinical and work-related interventions is recommended for improving health and increasing RTW, especially for patients with MSD on long-term sick leave $(9,33$, 46). We found that RIMs were widely applied and the specific judgment of usefulness was good. However, only one-third of cases received a combination of at least two RIMs and one-third received WI. A combination of intervention modalities may not always be indicated and it is more expensive compared with single intervention modalities for patients with back pain (55). The health- and work-related benefits of interventions need to be evaluated in relation to direct health care costs and costs due to absence from paid work. The appropriate choice of tailored uni- or multimodal intervention is rather a matter of identifying modifiable obstacles for RTW related to the sick-listed patient's personal health characteristics and life and work situations. In clinical practice, resources for health care providers working together are limited and access to interventions with a specific work focus was not provided as suggested by previous research.

\section{Strengths and Study Limitations}

The recruitment strategy was based on a representative sample of newly sick-listed individuals defined by ICD-10 according to a physician's judgment. Patients were not randomly assigned to interventions, instead the study population were analysed based on the type of intervention they received. The study design enabled us to follow three types of rehabilitation processes, namely medical interventions, clinical rehabilitative interventions and the group who reported that they received work-related interventions in combination with the other treatment strategies. The analyses differentiated between the amount of intervention they received.

Few studies include patients with MSD or MD, mainly because they have different kinds of health-related problems, causes of sick leave may differ and the interventions need to be tailored according to the patient's symptoms, needs, and life and working conditions. Nevertheless, these patient groups are frequent visitors in health care and experiences of sickness absence and prerequisites for RTW have similarities no matter what the cause of sick leave $(8,20)$. The 
newly sick-listed were recruited from most (39 units) of the primary health care centres in the county of Östergötland, Sweden, and from five occupational health service units. Östergötland has about 450,000 inhabitants and is representative of Sweden socioeconomically. Our findings can be generalized to the Swedish working population at large and can be considered to have high external validity. The distribution regarding diagnosis is similar in previous Swedish studies $(2,4)$. Lidwall et al. (3) found that long-term sick leave was associated with female sex and with various aspects of psychosocial work environment and work-related situations.

Improvement in work ability is commonly used as an outcome measure for evaluating return to interventions $(9,56)$. Alavina et al. (36) found that all of the separate scales in the WAI had predictive power for future disability with the highest influence of current work ability in relation to job demand. Based on previous research, we used the single item "current work ability compared with lifetime best" for measurement of work ability $(35,36)$. The longitudinal design of the study enabled us to measure work ability at baseline and at follow-up, evaluating the change in patient-reported work ability over time.

There are some limitations of the present study that that needs to be acknowledged. Several of the measurements used in the study were only captured at baseline or at 3-month follow-up. On the one hand, a weakness was the use of non-standardized self-reported measures for evaluating the type and usefulness of interventions, saying that part of the study is cross-sectional and part of it is a prospective cohort study. On the other hand, we wanted to capture the patient's judgment of usefulness related to work ability and interventions given in the rehabilitation process. Therefore, a follow-up questionnaire specifically designed for the research questions and focusing on which patients received what type of intervention was used. In this study, the patients were specifically asked about the effect on work ability due to health care contacts on a 5-point scale and therefore the results were presented as patients' reported effect on work ability, which may be used as an indication of patients' judgment.

\section{Clinical Implications and Future Studies}

As suggested, evidence-based practice (EBP) includes perspectives of patient preferences, clinical expertise, and the use of best available evidence (57). In the present study, both professional judgment (ICD-10) and patients' judgment were used, although there seems to be a gap between scientific evidence and praxis behaviour in the rehabilitation process. Future studies should strive to explore praxis behaviour comprising preferences of interventions not only from the patients' perspective but also from the employers' perspective, and include judgment of 
interventions. As previously reported (47), what type of interventions patients receive and the outcome of the rehabilitation process may be influenced by several factors such as patients' age, educational level and expectations for RTW.

According to our findings the treatment approach to sick-listed patients is still very medical and clinically oriented and involvement from employers in the rehabilitation process is scarce. Even if more research is needed in the future using RCTs to evaluate the effect of different interventions, the present study indicates that combined interventions are better than single interventions in terms of patients judgment of work ability.

Our findings have implications for employers with responsibility for the rehabilitation of sicklisted employees. Increased cooperation between the employer, health care professionals and the sick-listed employee is essential for a successful rehabilitation process, and work-related interventions should be provided if indicated.

Furthermore, a take-home message of this study is that for patients with MSD, behavioural treatment seems to be underutilized in clinical practice considering the effect it may have on developing coping strategies and reducing symptoms. In order to meet the recommendations in the guidelines, physical activity needs to increase as a treatment strategy for patients with MD. A future challenge is to assess who needs medical interventions, rehabilitative interventions, and work-related interventions, and who needs a combination of these interventions using a multimodal approach, and to evaluate the amount and duration of different interventions in relation to whether they are cost-effective or not.

\section{Conclusion}

Patients with MD who received a combination of work-related and clinical interventions reported best usefulness and best improvement of work ability. There was no difference in improvements in work ability between rehabilitation methods in the MSD group. Patients in both diagnostic groups reported high usefulness of behavioural treatment, ergonomic interventions, physical activity or manual treatment but these were seldom used as combined treatment strategies. What patients perceive as useful interventions and what they actually receive only partially match. There seems to be a gap between scientific evidence and praxis behaviour in the rehabilitation process. Unimodal rehabilitation was widely applied in the early rehabilitation process, a multimodal treatment approach was rare and only one-third received work-related interventions. It remains a challenge to understand who needs what type of intervention. 


\section{Acknowledgements}

This study was supported by grants from the Swedish Council for Working Life and Social Research (FAS) and from the County Council of Östergötland. The authors would like to thank all the participants in the Return to Work East Sweden Study, health care providers who were involved in the study and Henrik Magnusson for statistical support. 


\section{References}

1. Wahlin-Norgren C, Ekberg K, Oberg B. Is an expert diagnosis enough for assessment of sick leave for employees with musculoskeletal and mental disorders? Disabil Rehabil. 2011; 33(13-14):1147-56.

2. Eriksson HG, von Celsing AS, Wahlstrom R, Janson L, Zander V, Wallman T. Sickness absence and self-reported health a population-based study of 43,600 individuals in central Sweden. BMC Public Health. 2008;8:426.

3. Lidwall U, Bergendorff S, Voss M, Marklund S. Long-term sickness absence: changes in risk factors and the population at risk. Int J Occup Med Environ Health. 2009; 22(2):15768.

4. Vaez M, Hagberg J, Alexanderson K. The panorama of future sick-leave diagnoses among young adults initially long-term sickness absent due to neck, shoulder, or back diagnoses. An 11-year prospective cohort study. BMC Musculoskelet Disord. 2009; $10: 84$.

5. Anema JR, Schellart AJ, Cassidy JD, Loisel P, Veerman TJ, van der Beek AJ. Can cross country differences in return-to-work after chronic occupational back pain be explained? An exploratory analysis on disability policies in a six country cohort study. J Occup Rehabil. 2009;19(4):419-26.

6. Brouwers EP, Terluin B, Tiemens BG, Verhaak PF. Predicting return to work in employees sick-listed due to minor mental disorders. J Occup Rehabil. 2009;19(4):32332.

7. Lambeek LC, van Mechelen W, Buijs PC, Loisel P, Anema JR. An integrated care program to prevent work disability due to chronic low back pain: a process evaluation within a randomized controlled trial. BMC Musculoskelet Disord. 2009.10:147.

8. Vlasveld MC, van der Feltz-Cornelis CM, Bultmann U, Beekman AT, van Mechelen W, Hoedeman R, Anema JR. Predicting return to work in workers with all-cause sickness absence greater than 4 weeks: a prospective cohort study. J Occup Rehabil. 2012;22:118126 
9. Kuoppala J, Lamminpaa A. Rehabilitation and work ability: a systematic literature review. J Rehabil Med. 2008;40(10):796-804.

10. Franche RL, Cullen K, Clarke J, Irvin E, Sinclair S, Frank J. Workplace-based return-towork interventions: a systematic review of the quantitative literature. J Occup Rehabil. 2005;15(4):607-31.

11. Lotters FJ, Foets M, Burdorf A. Work and health, a blind spot in curative healthcare? A pilot study. J Occup Rehabil. 2011;21(3):304-12.

12. Shaw WS, van der Windt DA, Main CJ, Loisel P, Linton SJ. Early patient screening and intervention to address individual-level occupational factors ("blue flags") in back disability. J Occup Rehabil. 2009;19(1): 64-80.

13. Steenstra IA, Ibrahim SA, Franche RL, Hogg-Johnson S, Shaw WS, Pransky GS. Validation of a risk factor-based intervention strategy model using data from the readiness for return to work cohort study. J Occup Rehabil. 2010;20(3): 394-405.

14. Anema JR, Jettinghoff K, Houtman I, Schoemaker CG, Buijs PC, van den Berg R. Medical care of employees long-term sick listed due to mental health problems: a cohort study to describe and compare the care of the occupational physician and the general practitioner. J Occup Rehabil. 2006;16(1): 41-52.

15. Waddell G, Burton AK. Concepts of rehabilitation for the management of low back pain. Best Pract Res Clin Rheumatol. 2005;19(4): 655-70.

16. Heijbel B, Josephson M, Jensen I, Vingard E. Employer, insurance, and health system response to long-term sick leave in the public sector: policy implications. J Occup Rehabil. 2005;15(2):167-76.

17. Kosny A, Franche RL, Pole J, Krause N, Cote P, Mustard C. Early healthcare provider communication with patients and their workplace following a lost-time claim for an occupational musculoskeletal injury. J Occup Rehabil. 2006;16(1):27-39.

18. van Oostrom SH, van Mechelen W, Terluin B, de Vet HC, Knol DL, Anema JR. A workplace intervention for sick-listed employees with distress: results of a randomised controlled trial. Occup Environ Med. 2010; 67(9): 596-602. 
19. Hubertsson J, Petersson IF, Arvidsson B, Thorstensson CA. Sickness absence in musculoskeletal disorders - patients' experiences of interactions with the social insurance agency and health care. A qualitative study. BMC Public Health. 2011;11:107.

20. Haugli L, Maeland S, Magnussen LH. What facilitates return to work? Patients experiences 3 years after occupational rehabilitation. J Occup Rehabil. 2011;21(4): 57381.

21. de Vries G, Koeter MW, Nabitz U, Hees HL, Schene AH. Return to work after sick leave due to depression. A conceptual analysis based on perspectives of patients, supervisors and occupational physicians. J Affect Disord. 2011;136(3):1017-26.

22. Noordik E, Nieuwenhuijsen K, Varekamp I, van der Klink JJ, van Dijk FJ. Exploring the return-to-work process for workers partially returned to work and partially on long-term sick leave due to common mental disorders: a qualitative study. Disabil Rehabil. 2011;33(17-18):1625-35.

23. De Rijk A, Janssen N, Alexanderson K, Nijhuis F. Gender differences in return to work patterns among sickness absentees and their associations with health: a prospective cohort study in The Netherlands. Int J Rehabil Res. 2008;31(4):327-36.

24. Stein MB, Roy-Byrne PP, Craske MG, Campbell-Sills L, Lang AJ, Golinelli D, et al. Quality of and patient satisfaction with primary health care for anxiety disorders. J Clin Psychiatry. 2011;72(7): 970-6.

25. Linton SJ, Hellsing AL, Hallden K. A population-based study of spinal pain among 3545-year-old individuals. Prevalence, sick leave, and health care use. Spine. 1998; 23(13):1457-63.

26. Picavet HS, Struijs JN, Westert GP. Utilization of health resources due to low back pain: survey and registered data compared. Spine. 2008;33(4):436-44.

27. Mortimer M, Ahlberg G. To seek or not to seek? Care-seeking behaviour among people with low-back pain. Scand J Public Health. 2003;31(3):194-203.

28. Dionne CE, Bourbonnais R, Fremont P, Rossignol M, Stock SR, Nouwen A, et al. Determinants of "return to work in good health" among workers with back pain who 
consult in primary care settings: a 2-year prospective study. Eur Spine J. 2007;16(5):64155.

29. Dwight-Johnson M, Sherbourne CD, Liao D, Wells KB. Treatment preferences among depressed primary care patients. J Gen Intern Med. 2000;15(8):527-34.

30. Åsenlöf P, Denison E, Lindberg P. Long-term follow-up of tailored behavioural treatment and exercise based physical therapy in persistent musculoskeletal pain: a randomized controlled trial in primary care. Eur J Pain. 2009;13(10):1080-8.

31. Mergl R, Henkel V, Allgaier AK, Kramer D, Hautzinger M, Kohnen R, et al. Are treatment preferences relevant in response to serotonergic antidepressants and cognitivebehavioral therapy in depressed primary care patients? Results from a randomized controlled trial including a patients' choice arm. Psychother Psychosom. 2011;80(1): 3947.

32. Young AE, Roessler RT, Wasiak R, McPherson KM, van Poppel MN, Anema JR. A developmental conceptualization of return to work. J Occup Rehabil. 2005;15(4):557-68.

33. Stapelfeldt CM, Christiansen DH, Jensen OK, Nielsen CV, Petersen KD, Jensen C. Subgroup analyses on return to work in sick-listed employees with low back pain in a randomised trial comparing brief and multidisciplinary intervention. BMC Musculoskelet Disord. 2011;12:112.

34. Tuomi K, Ilmarinen J, Jahkola A, Katajarinne L, Tulkki A. Work ability index. 2nd revised ed. Helsinki: Finnish Institute of Occupational Health, Helsinki,; 1998.

35. Ahlstrom L, Grimby-Ekman A, Hagberg M, Dellve L. The work ability index and singleitem question: associations with sick leave, symptoms, and health--a prospective study of women on long-term sick leave. Scand J Work Environ Health. 2010;36(5): 404-12.

36. Alavinia SM, de Boer AG, van Duivenbooden JC, Frings-Dresen MH, Burdorf A. Determinants of work ability and its predictive value for disability. Occup Med (Lond). 2009;59(1): 32-7. 
37. George SZ, Robinson ME. Preference, expectation, and satisfaction in a clinical trial of behavioral interventions for acute and sub-acute low back pain. J Pain. 2010;11(11): 1074-82.

38. Wickizer TM, Franklin G, Fulton-Kehoe D, Turner JA, Mootz R, Smith-Weller T. Patient satisfaction, treatment experience, and disability outcomes in a population-based cohort of injured workers in Washington State: implications for quality improvement. Health Serv Res. 2004;39(4 Pt 1):727-48.

39. Sieurin L, Josephson M, Vingard E. Positive and negative consequences of sick leave for the individual, with special focus on part-time sick leave. Scand J Public Health. 2009; 37(1):50-6.

40. Michie S, Williams S. Reducing work related psychological ill health and sickness absence: a systematic literature review. Occup Environ Med. 2003;60(1):3-9.

41. Hultin H, Hallqvist J, Alexanderson K, Johansson G, Lindholm C, Lundberg I, et al. Work-related psychosocial events as triggers of sick leave--results from a Swedish casecrossover study. BMC Public Health. 2011;11:175.

42. Schultz IZ, Stowell AW, Feuerstein M, Gatchel RJ. Models of return to work for musculoskeletal disorders. J Occup Rehabil. 2007;17(2):327-52.

43. Burstrom B, Nylen L, Clayton S, Whitehead M. How equitable is vocational rehabilitation in Sweden? A review of evidence on the implementation of a national policy framework. Disabil Rehabil. 2011;33(6):453-66.

44. Karlson B, Jonsson P, Palsson B, Abjornsson G, Malmberg B, Larsson B, et al. Return to work after a workplace-oriented intervention for patients on sick-leave for burnout--a prospective controlled study. BMC Public Health. 2010;10:301.

45. Carroll C, Rick J, Pilgrim H, Cameron J, Hillage J. Workplace involvement improves return to work rates among employees with back pain on long-term sick leave: a systematic review of the effectiveness and cost-effectiveness of interventions. Disabil Rehabil. 2010;32(8):607-21. 
46. Lambeek LC, van Mechelen W, Knol DL, Loisel P, Anema JR. Randomised controlled trial of integrated care to reduce disability from chronic low back pain in working and private life. BMJ. 2010; 340: c1035.

47. Wåhlin C, Ekberg K, Persson J, Bernfort L, Öberg B. Association between clinical and work-related interventions and return-to-work for patients with musculoskeletal or mental disorders. J Rehabil Med. 2012;44:355-62.

48. Coole C, Watson PJ. Drummond A, Low back pain patients' experiences of work modifications; a qualitative study. BMC Musculoskelet Disord. 2010;11:277.

49. Lang AJ. Mental health treatment preferences of primary care patients. J Behav Med. 2005;28(6):581-6.

50. Krogh J, Nordentoft M, Sterne JA, Lawlor DA. The effect of exercise in clinically depressed adults: systematic review and meta-analysis of randomized controlled trials. $\mathbf{J}$ Clin Psychiatry. 2011;72(4):529-38.

51. Socialstyrelsen. Nationella riktlinjer för vård vid depression och ångestsyndrom 2010 . Stockholm: Socialstyrelsen; 2010.

52. Wetherell JL, Afari N, Rutledge T, Sorrell JT, Stoddard JA, Petkus AJ, et al. A randomized, controlled trial of acceptance and commitment therapy and cognitivebehavioral therapy for chronic pain. Pain. 2011;152(9):2098-107.

53. Koes BW, van Tulder M, Lin CW, Macedo LG, McAuley J, Maher C. An updated overview of clinical guidelines for the management of non-specific low back pain in primary care. Eur Spine J. 2010;19(12):2075-94.

54. Statens beredning för medicinsk utvärdering, Rehabilitering vid långvarig smärta. En systematisk litteraturöversikt [Rehabilitation of patients with chronic pain conditions. A systematic review]. Stockholm: The Swedish Council on Technology Assessment in Health Care; 2010.

55. Smeets RJ, Severens JL, Beelen S, Vlaeyen JW, Knottnerus JA. More is not always better: cost-effectiveness analysis of combined, single behavioral and single physical rehabilitation programs for chronic low back pain. Eur J Pain. 2009;13(1):71-81. 
56. Braathen TN, Veiersted KB, Heggenes J. Improved work ability and return to work following vocational multidisciplinary rehabilitation of subjects on long-term sick leave. J Rehabil Med. 2007;39(6):493-9.

57. Satterfield JM, Spring B, Brownson RC, Mullen EJ, Newhouse RP, Walker BB, et al. Toward a transdisciplinary model of evidence-based practice. Milbank Q. 2009; 87(2): 368-90. 
Table 1. Baseline characteristics of the study population $(n=810)$ presented in subgroups of musculoskeletal disorders (MSD) and mental disorders (MD) as a percentage and frequency $(n)$

\begin{tabular}{|c|c|c|c|}
\hline Variables & $\begin{array}{l}\text { MSD, \% (n) } \\
(n=499)\end{array}$ & $\begin{array}{l}\text { MD, \% (n) } \\
(n=311)\end{array}$ & $p$-value \\
\hline Sex & & & $<0.001$ \\
\hline Female & $66(327)$ & $82(256)$ & \\
\hline Male & $34(172)$ & $18(55)$ & \\
\hline Age & & & $<0.001$ \\
\hline 20-29 years & $7(33)$ & $10(32)$ & \\
\hline $30-39$ years & $16(80)$ & $24(74)$ & \\
\hline $40-49$ years & 27 (137) & $37(115)$ & \\
\hline $50-59$ years & $34(169)$ & $18(57)$ & \\
\hline $60-65$ years & $16(80)$ & $11(33)$ & \\
\hline Marital status & & & n.s. \\
\hline Married/living together & $78(381)$ & $75(229)$ & \\
\hline Living alone/other & $22(110)$ & $25(78)$ & \\
\hline Educational level & & & $<0.001$ \\
\hline $\begin{array}{l}\text { Lower education (mandatory and high } \\
\text { school) }\end{array}$ & $81(399)$ & $60(184)$ & \\
\hline Higher education (University) & $19(91)$ & $40(124)$ & \\
\hline Occupational category & & & $<0.001$ \\
\hline White collar & $18(84)$ & $44(129)$ & \\
\hline Pink collar & $42(191)$ & $42(121)$ & \\
\hline Blue collar & $40(183)$ & $14(41)$ & \\
\hline Sick leave & & & $<0.05$ \\
\hline Full time $(100 \%)$ & $73(338)$ & $63(181)$ & \\
\hline Part time $(75 \%)$ & $1(5)$ & $2(7)$ & \\
\hline Part time $(50 \%)$ & $21(96)$ & $27(77)$ & \\
\hline Part time (25\%) & $5(21)$ & $8(22)$ & \\
\hline
\end{tabular}


Table 2. Frequency of intervention, judgment of specific usefulness of medical intervention modalities and rehabilitative intervention modalities (RIMs), and frequency of work-related interventions presented in diagnostic groups as percentages, frequencies $(n)$, means and SD

Type of intervention

$$
\begin{aligned}
& \text { Frequency, \% (n) Level of } \\
& \text { significance } \\
& \text { MSD MD } \\
& (n=499) \quad(n=311)
\end{aligned}
$$

\begin{tabular}{|c|c|c|c|c|c|c|}
\hline Medical treatment & $52(257)$ & $62(192)$ & $*$ & $3.2(1.2)$ & $3.8(1.0)$ & $* * *$ \\
\hline Medical investigation & $34(169)$ & $30(92)$ & n.s. & $3.1(1.2)$ & $3.5(1.2)$ & $*$ \\
\hline Other MI & $6(32)$ & $6(17)$ & n.s. & $3.0(1.4)$ & $2.8(1.2)$ & n.s. \\
\hline \multicolumn{7}{|c|}{ Type of rehabilitative intervention modalities } \\
\hline Health care advice & $23(113)$ & $37(116)$ & $* * *$ & $3.7(1.2)$ & $4.0(0.9)$ & $*$ \\
\hline Behavioural treatment & $10(51)$ & $65(202)$ & $* * *$ & $3.9(1.2)$ & $4.1(0.9)$ & n.s. \\
\hline $\begin{array}{l}\text { Exercise therapy/physical } \\
\text { activity }\end{array}$ & $41(203)$ & $7(22)$ & $* * *$ & $3.8(1.1)$ & $4.0(0.8)$ & n.s \\
\hline Manual treatment & $34(170)$ & $12(37)$ & $* * *$ & $3.9(1.0)$ & $4.2(0.8)$ & n.s \\
\hline $\begin{array}{l}\text { Ergonomic, } \\
\text { equipment/orthosis }\end{array}$ & $8(39)$ & $1(3)$ & $* * *$ & $3.6(1.1)$ & $3.7(1.1)$ & n.s \\
\hline \multirow[t]{3}{*}{ Other RIMs } & $4(21)$ & $2(5)$ & $*$ & $2.6(1.3)$ & $2.6(1.7)$ & n.s \\
\hline & $\begin{array}{l}\text { MSD, } \% \\
(n)\end{array}$ & \multicolumn{2}{|l|}{$\mathrm{MD}, \%(n)$} & & & \\
\hline & $25(125)$ & $40(124)$ & $* * *$ & & & \\
\hline
\end{tabular}

Level of significance

Type of medical intervention modalities

\section{Type of work-related intervention}

$\begin{array}{lccc}\text { Ergonomic } & 23(29) & 2(3) & * * * \\ \begin{array}{l}\text { Adjustments to work } \\ \text { task/work environment }\end{array} & 42(53) & 43(53) & \text { n.s. } \\ \begin{array}{l}\text { Change of work } \\ \text { task/employment }\end{array} & 14(17) & 18(22) & \text { n.s. } \\ \begin{array}{l}\text { Adaptation of working } \\ \text { hours/organizational change }\end{array} & 21(26) & 30(37) & \text { n.s. } \\ \begin{array}{l}\text { Rehabilitation support } \\ 18(23)\end{array} & 31(38) & *\end{array}$

MD, mental disorders; MSD, musculoskeletal disorders. Levels of significance: ${ }^{*} p<0.05$; $* * p<0.01 ; * * * p<0.001$.

${ }^{\mathrm{a}}$ The scale runs from 5 (very good) to 1 (very poor). 
Table 3. Patient-reported usefulness of interventions, mean work ability score (SD) and effect of health care contacts presented for the total study population $(n=810)$ divided into intervention groups and diagnostic groups as percentages and frequencies (n)

\begin{tabular}{|c|c|c|c|c|c|c|c|c|}
\hline \multirow[t]{2}{*}{ Variables } & \multicolumn{4}{|c|}{ Patients with MSD, mean (SD) $(n=499)$} & \multicolumn{4}{|c|}{ Patients with MD, mean (SD) $(n=311)$} \\
\hline & $\begin{array}{l}\text { MI } \\
\text { group }(n=139)\end{array}$ & $\begin{array}{l}\text { CRI } \\
\text { group } \\
(n=235)\end{array}$ & $\begin{array}{l}\text { WI } \\
\text { group } \\
(n=125)\end{array}$ & $p$-value & $\begin{array}{l}\text { MI } \\
\text { group } \\
(n=54)\end{array}$ & $\begin{array}{l}\text { CRI } \\
\text { group } \\
(n=133)\end{array}$ & $\begin{array}{l}\text { WI } \\
\text { group } \\
(n=124)\end{array}$ & $p$-value \\
\hline $\begin{array}{l}\text { Work ability } \\
(0-10) \text { baseline }\end{array}$ & $3.9(3.3)$ & $3.2(2.8)$ & $3.6(2.8)$ & n.s. & $\begin{array}{l}4.7 \\
(2.7)\end{array}$ & $3.4(2.8)$ & $3.2(2.7)$ & $\begin{array}{l}\mathrm{CRI}<\mathrm{MI}^{*} ; \\
\mathrm{WI}<\mathrm{MI}^{* *}\end{array}$ \\
\hline $\begin{array}{l}\text { Work ability } \\
(0-10) 3 \text { months }\end{array}$ & $6.5(3.1)$ & $5.2(3.2)$ & $5.8(2.8)$ & $\mathrm{CRI}<\mathrm{MI} * * *$ & $\begin{array}{l}7.2 \\
(2.4)\end{array}$ & $5.4(3.2)$ & $6.5(2.6)$ & $\begin{array}{l}\mathrm{CRI}<\mathrm{MI} \mathrm{I}^{* * *} ; \\
\mathrm{CRI}<\mathrm{WI} *\end{array}$ \\
\hline $\begin{array}{l}\text { Change in work } \\
\text { ability baseline to } 3 \\
\text { months }\end{array}$ & $2.6(3.6)$ & $2.0(3.4)$ & $2.2(3.1)$ & n.s. & $\begin{array}{l}2.5 \\
(3.0)\end{array}$ & $2.0(3.2)$ & $3.2(2.9)$ & $\mathrm{CRI}<\mathrm{WI} *$ \\
\hline $\begin{array}{l}\text { Overall judgment } \\
\text { of usefulness of } \\
\text { interventions }^{\mathrm{a}}\end{array}$ & $3.1(1.1)$ & $3.2(1.2)$ & $3.4(1.1)$ & $\mathrm{MI}<\mathrm{WI} *$ & $\begin{array}{l}3.4 \\
(1.2)\end{array}$ & $3.7(0.9)$ & $4.1(0.8)$ & $\begin{array}{l}\mathrm{MI}<\mathrm{WI} * * * ; \\
\mathrm{CRI}<\mathrm{WI} *\end{array}$ \\
\hline $\begin{array}{l}\text { Patient-reported } \\
\text { effect of health } \\
\text { care contacts on } \\
\text { work ability, \% (n) }\end{array}$ & & & & n.s. & & & & $\begin{array}{l}\mathrm{MI}<\mathrm{WI} * * ; \\
\mathrm{CRI}<\mathrm{WI} * * *\end{array}$ \\
\hline Yes, improved & $46(62)$ & $50(113)$ & $58(71)$ & & $57(28)$ & $58(74)$ & $82(99)$ & \\
\hline Not improved & $54(72)$ & $50(112)$ & $42(51)$ & & $43(21)$ & $42(53$ & $18(22)$ & \\
\hline
\end{tabular}

CRI, clinical rehabilitative intervention; MD, mental disorders; MI, medical intervention; MSD, musculoskeletal disorders; WI, work-related intervention. Level of significance: ${ }^{*} p<0.05$; $* * p<0.01 ; * * * p<0.001$.

${ }^{\mathrm{a}}$ The scale runs from 5 (very good) to 1 (very poor). 


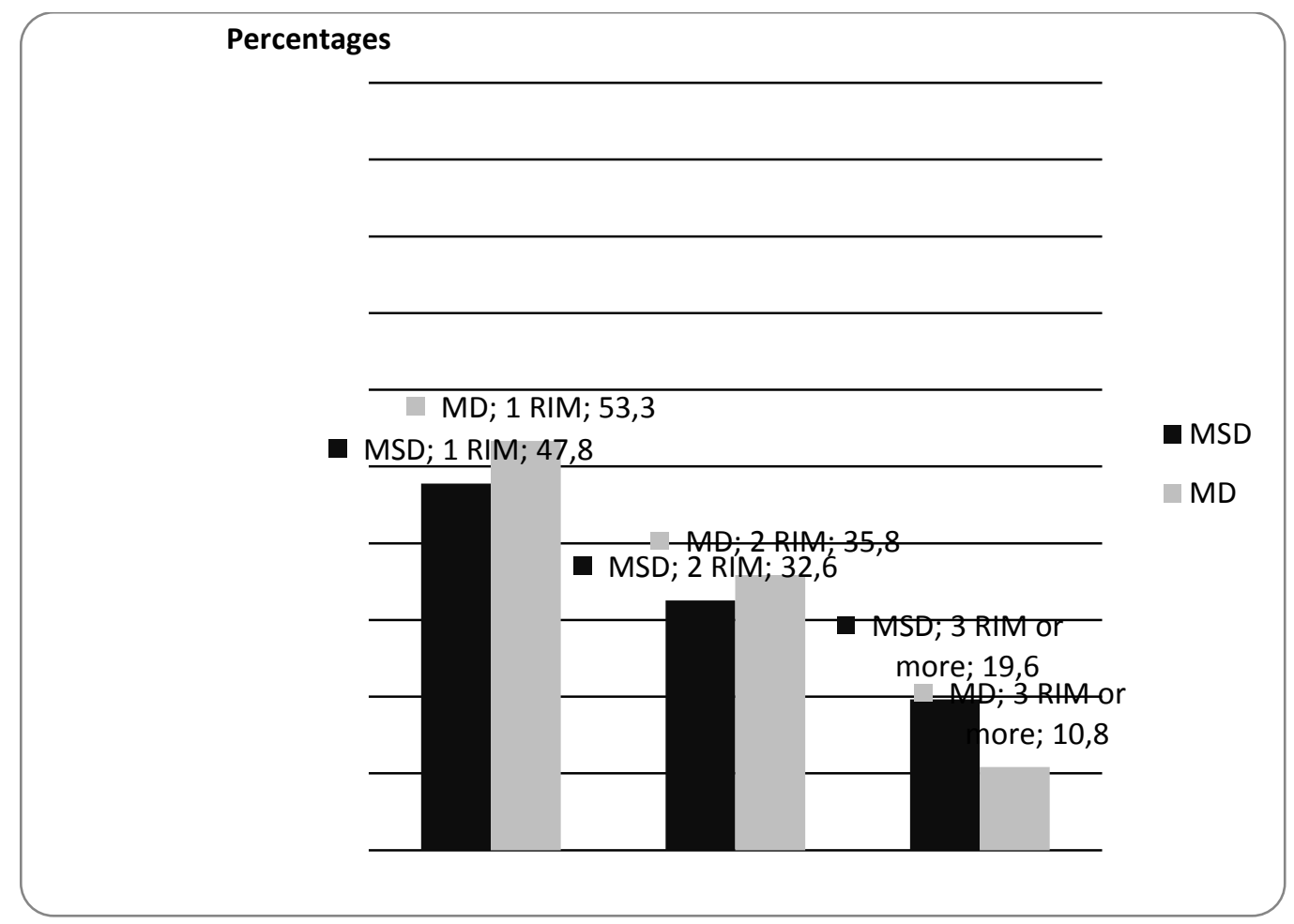

Fig. 1 Occurrence of one or more RIMs for 581 patients in the two diagnostic groups: MSD; musculoskeletal disorders $(n=341)$; MD, mental disorders $(n=240)$. 